\title{
Investigation of Grid-connected Voltage Source Converter Performance under Unbalanced Faults
}

\author{
Jia, Jundi; Yang, Guangya; Nielsen, Arne Hejde
}

Published in:

Proceedings of 2016 IEEE PES Asia-Pacific Power and Energy Conference

Link to article, DOI:

10.1109/APPEEC.2016.7779576

Publication date:

2016

Document Version

Peer reviewed version

Link back to DTU Orbit

Citation (APA):

Jia, J., Yang, G., \& Nielsen, A. H. (2016). Investigation of Grid-connected Voltage Source Converter Performance under Unbalanced Faults. In Proceedings of 2016 IEEE PES Asia-Pacific Power and Energy Conference (pp. 609-613). IEEE. https://doi.org/10.1109/APPEEC.2016.7779576

\section{General rights}

Copyright and moral rights for the publications made accessible in the public portal are retained by the authors and/or other copyright owners and it is a condition of accessing publications that users recognise and abide by the legal requirements associated with these rights.

- Users may download and print one copy of any publication from the public portal for the purpose of private study or research.

- You may not further distribute the material or use it for any profit-making activity or commercial gain

- You may freely distribute the URL identifying the publication in the public portal 


\title{
Investigation of Grid-connected Voltage Source Converter Performance under Unbalanced Faults
}

\author{
Jundi Jia, Guangya Yang, Senior Memer, IEEE, and Arne Hejde Nielsen, Senior Memer, IEEE \\ Department of Electrical Engineering \\ Technical University of Denmark \\ Kongens Lyngby, Denmark \\ junjia@elektro.dtu.dk,gyy@elektro.dtu.dk, ahn@elektro.dtu.dk
}

\begin{abstract}
Renewable energy sources (RES) and HVDC links are typically interfaced with the grid by power converters, whose performance during grid faults is significantly different from that of traditional synchronous generators. This paper investigates the performance of grid-connected voltage source converters (VSCs) under unbalanced faults. Conventional positive-sequence synchronous reference frame (SRF) control is presented first, followed by three different negative-sequence current control strategies considering reactive power injection and converter current limit. The simulation results indicate that the performance of VSCs varies with their control strategies. Negative-sequence current control is necessary to restrict converter current in each phase under unbalanced faults. Among presented control strategies, the balanced current control strategy complies with the present voltage support requirement best and further requirements should be specified if a set of controlled unbalanced current is expected under unbalanced faults.
\end{abstract}

Index Terms-Converter control; fault ride through; reactive power; short circuit current; unbalanced faults.

\section{INTRODUCTION}

Due to a growing concern about climate change, an increasing amount of RES has been integrated into power system. According to Danish Energy Agency, the share of renewable energy will increase to $33 \%$ by 2020 and it is expected that the energy supply should be based on $100 \%$ renewable energy by 2050 , thus eliminating dependency on fossil fuels [1]. Conventional fossil-fuel-based power plants consist of large synchronous generators, being able to provide a large amount of fault current during system voltage dips. However, the fault current provided by power converters is restricted to only 1-2 pu depending on semiconductor capabilities. In addition, the characteristics of the fault current are primarily determined by the control system. As a result, the injected fault current might be significantly affected in a converter-based power system, which in turn could influence the reliability of protection system relying on voltage and current.

Voltage source converters are widely used in a variety of applications such as wind power plants, photovoltaic power plants and HVDC transmission. However, VSCs are sensitive to grid voltage dips and increasing requirements in terms of grid codes have been imposed by transmission system operators (TSOs) regarding fault-ride-through (FRT), voltage support, unbalanced current injection [2], etc. To assess the potential impact of grid-connected converters on protection system, it is necessary to investigate the performance of VSCs during faults taking grid codes into account. In [3]-[6], the impact of grid-connected VSCs on transmission-side protection is investigated. All these studies are based on balanced faults without considering unbalanced scenarios. The appearance of negative-sequence voltage under unbalanced faults leads to undesired converter performance such as distorted fault current and output power oscillations [7]. To be able to ride through unbalanced faults, considerable studies [8]-[11] have been carried out in the last decade. In [8] and [9], the performance of VSC-HVDC and Type-IV wind turbine is evaluated respectively without involving reactive power injection. Even though [10] and [11] take reactive power into consideration, simulation regarding severe fault conditions and converter current limit is left out.

In this paper, the performance of grid-connected VSCs under two-phase fault is investigated by adopting different control strategies. Both of reactive power injection and converter current limit are considered. All works are modeled and simulated in real time digital simulator (RTDS).

\section{Voltage SOURCE CONVERTER CONTROLS}

\section{A. Basic Configuration}

The basic configuration of a grid-connected two-level, three-phase VSC is shown in Fig. 1. It is connected to AC power system through a delta-star transformer. Typically, the control system of VSCs consists of an outer controller and an inner current controller. The outer controller aims to generate current references by regulating active power/DC-side voltage and reactive power/AC-side voltage, the combination of which depends on variable objectives. The inner current controller is designed to regulate current by tracking current references in order to generate output voltage vector reference of VSCs. To achieve grid synchronization, a phase-locked loop (PLL) is utilized to detect the phase angle of the grid-side voltage. The 
angle is essential for Park transformation that converts threephase signals into $d q$-form under rotating reference frame.

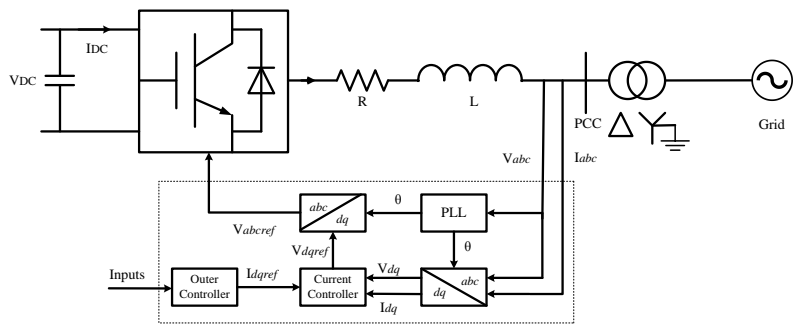

Figure 1. Configuration of a Grid-connected VSC System

\section{B. Positive-sequence SRF Control}

This control method enables the simplest implementation [8]. If DC-side voltage and reactive power are directly regulated, the control system can be represented by Fig. 2, where subscript "ref" denotes the reference value.

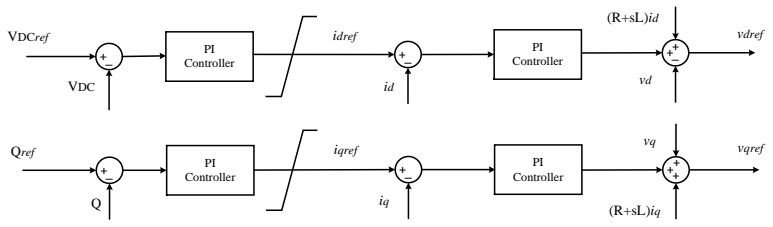

Figure 2. Configuration of Positive-sequence SRF control

Considering Danish Grid codes, the reactive current control should follow Fig. 3, which means that reactive current injection should increase by $2 \%$ for each $1 \%$ drop in PCC voltage [13]. As defined in [12], the first priority is given to the delivery of reactive power during voltage dips, while active power takes the second priority. Therefore, the active current $i_{d}$ is restricted according to:

$$
i_{d}=\sqrt{I_{\max }^{2}-i_{q}^{2}}
$$

where $I_{\max }$ represents the maximum allowed current flowing through converters.

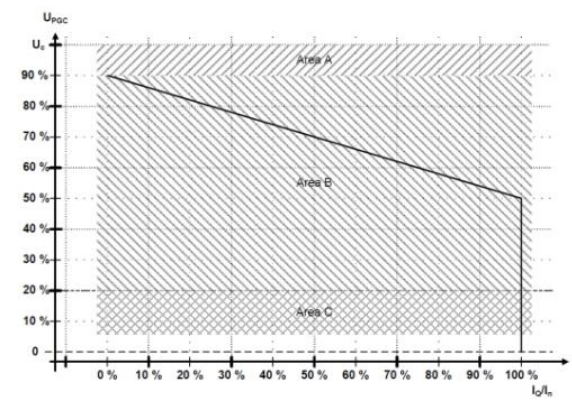

Figure 3. Reactive Current Injection During Voltage Dips [12]

However, negative-sequence voltage appears at PCC under unbalanced faults and which component of PCC voltage should be used in accordance with Fig. 3 is not defined. In this paper, both complete voltage and positive-sequence voltage are considered, and it is also assumed that " $I_{Q}$ " in Fig. 3 refers to positive-sequence component so that the requirement can still be satisfied for three-phase faults [12].

\section{Dual-sequence SRF Control}

Dual-sequence SRF control is firstly introduced in [14], where two sets of current controllers are used, one regulating $d q$-signals rotating in positive-sequence reference frame while the other one in negative-sequence reference frame rotating in an opposite direction. As shown in Fig. 4, the inner current controller is the same as that of positive-sequence SRF control. The only issue left is how to generate current references and set converter current limit.

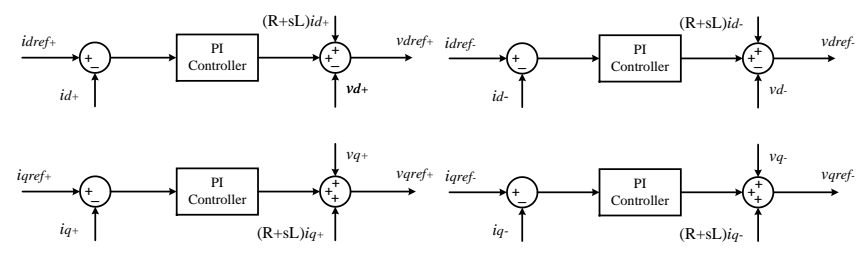

Figure 4. Configuration of Dual-sequence SRF Control

According to the instantaneous power theory, the output active and reactive power at PCC under unbalanced conditions can be expressed by [13]:

$$
\begin{aligned}
& p=P_{0}+P_{c 2} \cos (2 \omega t)+P_{s 2} \sin (2 \omega t) \\
& q=Q_{0}+Q_{c 2} \cos (2 \omega t)+P_{s 2} \sin (2 \omega t)
\end{aligned}
$$

where $\omega$ is the fundamental angular frequency; $P_{0}$ and $Q_{0}$ are constant terms while $P_{c 2}, P_{s 2}, Q_{c 2}$ and $Q_{s 2}$ are magnitudes of oscillating terms. If all the power terms are represented by sequence components (zero-sequence is neglected), there are:

$$
\begin{aligned}
P_{0} & =1.5\left(v_{d}^{+} i_{d}^{+}+v_{q}^{+} i_{q}^{+}+v_{d}^{-} i_{d}^{-}+v_{q}^{-} i_{q}^{-}\right) \\
P_{c 2} & =1.5\left(v_{d}^{-} i_{d}^{+}+v_{q}^{-} i_{q}^{+}+v_{d}^{+} i_{d}^{-}+v_{q}^{+} i_{q}^{-}\right) \\
P_{s 2} & =1.5\left(v_{q}^{-} i_{d}^{+}-v_{d}^{-} i_{q}^{+}-v_{q}^{+} i_{d}^{-}+v_{d}^{+} i_{q}^{-}\right) \\
Q_{0} & =1.5\left(v_{q}^{+} i_{d}^{+}-v_{d}^{+} i_{q}^{+}+v_{q}^{-} i_{d}^{-}-v_{d}^{-} i_{q}^{-}\right) \\
Q_{c 2} & =1.5\left(v_{q}^{-} i_{d}^{+}-v_{d}^{-} i_{q}^{+}+v_{q}^{+} i_{d}^{-}-v_{d}^{+} i_{q}^{-}\right) \\
Q_{s 2} & =1.5\left(-v_{d}^{-} i_{d}^{+}-v_{q}^{-} i_{q}^{+}+v_{d}^{+} i_{d}^{-}+v_{q}^{+} i_{q}^{-}\right)
\end{aligned}
$$

where subscripts " + " and "-" denote positive- and negativesequence components respectively. As indicated in Fig. 4, only four variables $\left(i_{d}^{+}, i_{q}^{+}, i_{d}^{-}\right.$and $\left.i_{q}^{-}\right)$can be regulated, meaning four out of six power terms can be freely controlled. If a set of balanced fault current is injected during unbalanced faults, the reference value of $i_{d}^{-}$and $i_{q}^{-}$should be set to zero. The current limiter given by (1) can be applied to positivesequence current. If constant active power is desired, the current references can be calculated using (4)-(7) by setting $P_{s 2}, P_{c 2}$ to zero and choosing proper values of $P_{0}$ and $Q_{0}$. Similarly, constant reactive power is achieved by setting $Q_{s 2}$ and $Q_{c 2}$ to zero. Current limit and reactive current injection for these two strategies will be discussed in the next section.

\section{Flexbile Control}

Flexible control means that extra coefficients, which can be freely adjusted in a specific range, are involved in reference current calculation so that a certain relationship among power terms is realized. Two strategies, namely "flexible oscillating power control" and "flexible positive- and negative-sequence power control" are reported in [10] and [11] respectively. 
1) Flexible Oscillating Power Control: If (2) and (3) are expressed using voltage and current vectors, the instantaneous active and reactive power become:

$$
\begin{aligned}
& p=\underbrace{\mathbf{v}^{+} \cdot \mathbf{i}^{+}+\mathbf{v}^{-} \cdot \mathbf{i}^{-}}_{P_{0}}+\underbrace{\mathbf{v}^{+} \cdot \mathbf{i}^{-}+\mathbf{v}^{-} \cdot \mathbf{i}^{-}}_{\tilde{P}} \\
& q=\underbrace{\mathbf{v}_{\perp}^{+} \cdot \mathbf{i}^{+}+\mathbf{v}_{\perp}^{-} \cdot \mathbf{i}^{-}}_{Q_{0}}+\underbrace{\mathbf{v}_{\perp}^{+} \cdot \mathbf{i}^{-}+\mathbf{v}_{\perp}^{-} \cdot \mathbf{i}^{+}}_{\tilde{Q}}
\end{aligned}
$$

where $\mathbf{v}$ and $\mathbf{i}$ represent voltage and current vector respectively; $\widetilde{P}$ and $\tilde{Q}$ denote oscillating active and reactive power; the operator " $\perp$ " refers to an orthogonal version of the associated vector, whose transfer matrix can be found in [10]. Two coefficients $k_{p}$ and $k_{q}$ are introduced as weighing factors for elimination of $\tilde{P}$ and $\tilde{Q}$ so that:

$$
\begin{aligned}
& \mathbf{v}^{+} \cdot \mathbf{i}^{-}=-k_{p} \mathbf{v}^{-} \cdot \mathbf{i}^{-} \\
& \mathbf{v}_{\perp}^{+} \cdot \mathbf{i}^{-}=-k_{q} \mathbf{v}_{\perp}^{-} \cdot \mathbf{i}^{+}
\end{aligned}
$$

Then the current references can be calculated by [10]:

$$
\begin{aligned}
& \mathbf{i}_{P}^{r e f}=\frac{P^{r e f}}{\left|\mathbf{v}^{+}\right|^{2}+k_{p}\left|\mathbf{v}^{-}\right|^{2}}\left(\mathbf{v}^{+}+k_{p} \mathbf{v}^{-}\right) \\
& \mathbf{i}_{Q}^{r e f}=\frac{Q^{r e f}}{\left|\mathbf{v}^{+}\right|^{2}+k_{q}\left|\mathbf{v}^{-}\right|^{2}}\left(\mathbf{v}_{\perp}^{+}+k_{q} \mathbf{v}_{\perp}^{-}\right)
\end{aligned}
$$

where $\mathbf{i}_{P}^{\text {ref }}$ and $\mathbf{i}_{Q}^{\text {ref }}$ are current vector references that control active and reactive power respectively; $P^{\text {ref }}$ and $Q^{\text {ref }}$ are active and reactive references that can be set directly or generated by other control loops. It should be mentioned that (14) and (15) are valid in different reference frames such as $d q$-frame, $\alpha \beta$-frame and $a b c$-frame [15].

If $k_{p}=-k_{q}=k(-1 \leq k \leq 1)$ is chosen, oscillations in active power is gradually reduced to zero with $\mathrm{k}$ moving from 1 to -1 . However, an oscillation reduction in either active or reactive power will give rise to oscillations in the other.

2) Flexible Positive- and Negative-sequence Power Control: According to (10) and (11), both positive- and negative-sequence current contribute to constant active and reactive power terms. Therefore, two coefficients are introduced to flexibly adjust the relationship between positiveand negative- sequence power so that:

$$
\begin{aligned}
& \mathbf{v}^{+} \cdot \mathbf{i}^{+}=k_{p} P^{r e f} \\
& \mathbf{v}^{-} \cdot \mathbf{i}^{-}=\left(1-k_{p}\right) P^{r e f} \\
& \mathbf{v}_{\perp}^{+} \cdot \mathbf{i}^{+}=k_{q} Q^{r e f} \\
& \mathbf{v}_{\perp}^{+} \cdot \mathbf{i}^{-}=\left(1-k_{q}\right) Q^{r e f}
\end{aligned}
$$

Then the current references are written as:

$$
\begin{aligned}
& \mathbf{i}_{P}^{\text {ref }}=k_{p} \frac{P^{r e f}}{\left|\mathbf{v}^{+}\right|^{2}} \mathbf{v}^{+}+\left(1-k_{p}\right) \frac{P^{r e f}}{\left|\mathbf{v}^{-}\right|^{2}} \mathbf{v}^{-} \\
& \mathbf{i}_{Q}^{r e f}=k_{q} \frac{Q^{r e f}}{\left|\mathbf{v}^{+}\right|^{2}} \mathbf{v}_{\perp}^{+}+\left(1-k_{q}\right) \frac{Q^{r e f}}{\left|\mathbf{v}^{-}\right|^{2}} \mathbf{v}_{\perp}^{-}
\end{aligned}
$$

It is suggested in [16] the two coefficients have the same sign so that $k_{p}=k_{q}=k(0 \leq k \leq 1)$, which has the capability of reducing oscillating active and reactive power at the same time.

In comparison, the two flexible control methods presented above are the same in essence. For example, if the two coefficients are selected following (22)-(24) for flexible positive- and negative-sequence power control, it is equivalent to flexible oscillating power control with $k_{p}=-k_{q}$. Therefore, as long as the relationship of $k_{p}$ and $k_{q}$ is determined in either flexible control method, there exists a fixed coefficient expression in the other one so that the two flexible methods are equivalent. Furthermore, flexible control is a more generic control scheme to generate current references as a compromise between different strategies can be achieved by properly choosing $k_{p}$ and $k_{q}$.

$$
\begin{gathered}
1 / k_{p}+1 / k_{q}=2 \\
\frac{\left|\mathbf{v}^{+}\right|^{2}}{\left|\mathbf{v}^{+}\right|^{2}+\left|\mathbf{v}^{-}\right|^{2}} \leq k_{p} \leq \frac{\left|\mathbf{v}^{+}\right|^{2}}{\left|\mathbf{v}^{+}\right|^{2}-\left|\mathbf{v}^{-}\right|^{2}} \\
\frac{\left|\mathbf{v}^{+}\right|^{2}}{\left|\mathbf{v}^{+}\right|^{2}+\left|\mathbf{v}^{-}\right|^{2}} \leq k_{q} \leq \frac{\left|\mathbf{v}^{+}\right|^{2}}{\left|\mathbf{v}^{+}\right|^{2}-\left|\mathbf{v}^{-}\right|^{2}}
\end{gathered}
$$

Considering a severe unbalanced fault when $\left|v^{+}\right|^{2} \approx$ $\left|\mathrm{v}^{-}\right|^{2}$, if constant active power is desired, the denominator of (14) will approach to zero since $k_{p}=-k_{q}=-1$, leading to a high value of $\mathbf{i}_{P}^{\text {ref }}$; if constant reactive power is selected by setting $k_{p}=-k_{q}=1$, a quite high value of $\mathbf{i}_{Q}^{\text {ref }}$ is obtained since the denominator of (13) tends to be zero. However, if a stiff current limiter acting on $i_{d}^{+}, i_{q}^{+}, i_{d}^{-}$and $i_{q}^{-}$like (1) is used, the expected constant active or reactive power cannot be realized anymore. Therefore, the values of $P^{r e f} /\left(\left|\mathbf{v}^{+}\right|^{2}+\right.$ $\left.k_{p}\left|\mathbf{v}^{-}\right|^{2}\right)$ and $Q^{r e f} /\left(\left|\mathbf{v}^{+}\right|^{2}+k_{q}\left|\mathbf{v}^{-}\right|^{2}\right)$ should be reduced in a proper way to avoid overcurrent in each phase. As presented in [15], each control strategy requires a specific analysis to restrict converter current for unbalanced faults. A detailed calculation procedure for proper value of $P^{\text {ref }}$ and $Q^{\text {ref }}$ regarding flexible positive- and negative sequence power control is introduced in [15]. Due to its complexity, it is not repeated here.

\section{Simulating Results}

In this paper, a VSC system with a capacity of 500 MVA shown in Fig. 1 is modeled in RTDS. It is connected to a grid through a $150 / 400 \mathrm{kV}$ step-up transformer, whose starconnected side is grounded. The short-circuit ratio at PCC is selected as 10. A constraint of $1.2 \mathrm{pu}$ is selected to limit converter current. In order to investigate the performance of VSCs under unbalanced faults, a phase A-B fault with zero fault resistance is applied at high-voltage side of the transformer at zero time instant so that $\left|\mathbf{v}^{+}\right|$is close to $\left|\mathbf{v}^{-}\right|$. Due to the choice of transformer, a two-phase fault on highvoltage side appears like a single-phase fault on low-voltage side. Before the fault is initiated, the VSC is delivering power at its full capacity with unity power factor.

\section{A. Positive-sequence SRF control}

Referring to Fig. 3, if a complete voltage at PCC is used, three-phase voltage, three-phase current, output power and positive-sequence reactive current (IRP) measured at PCC are 
plotted in Fig. 5 with per unit value, where the green lines represent $1.2 \mathrm{pu}$ converter current limit. When the positivesequence voltage is used in Fig.3, the dynamic response of the same variables is given in Fig. 6.

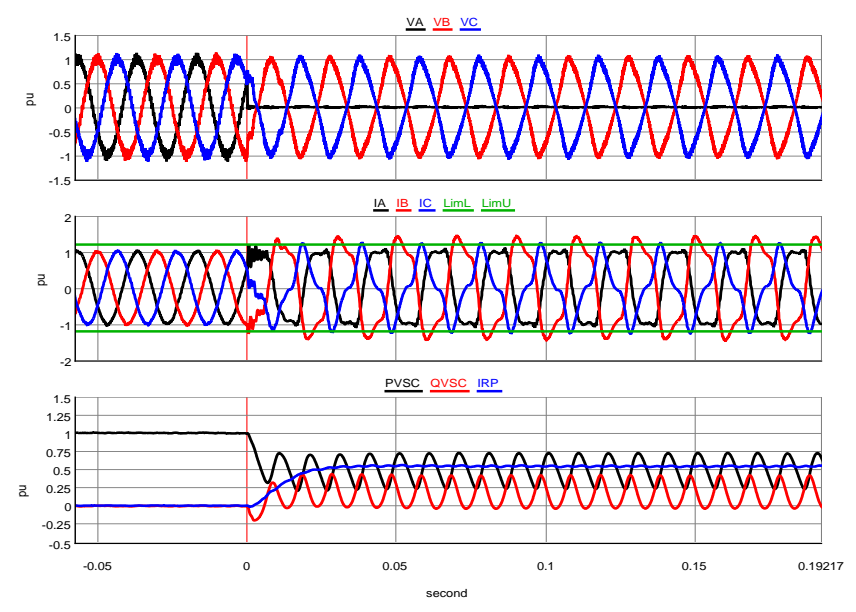

Figure 5. Simulation Results with Positive-sequence SRF Control (complete voltage at PCC is used in Fig.3)
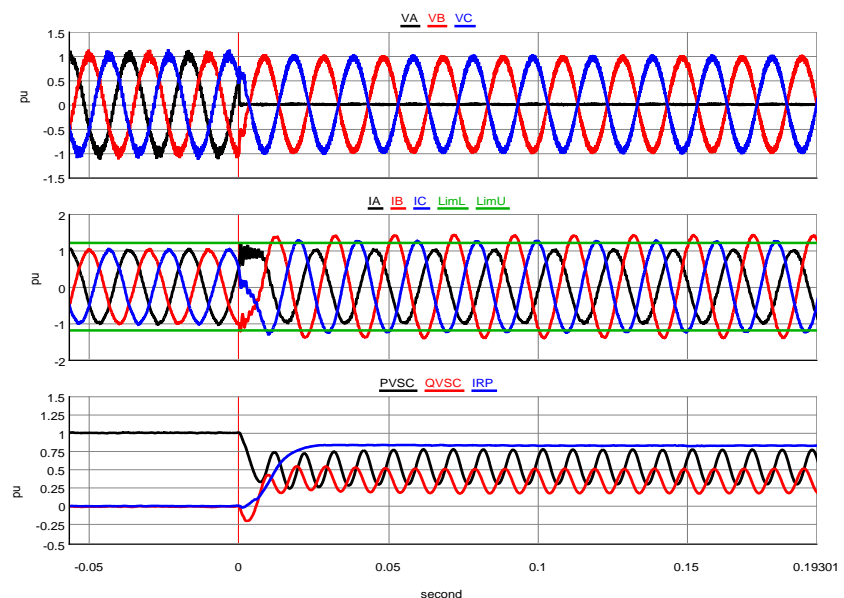

Figure 6. Simulation Results with Positive-sequence SRF Control (positive-sequence voltage at PCC is used in Fig.3)

In Fig. 5, the voltage and current at PCC exhibit distortion, whereas no distortion is observed in Fig. 6 . The reason is that the complete PCC voltage contains oscillations at twice fundamental frequency during unbalanced faults. If such a voltage is used, reference current in $q$-axis is not in DC value anymore. PI controller cannot track such current reference without steady-state error due to its limited bandwidth [14]. The utilization of positive-sequence voltage enables the current reference in $q$-axis to be in DC value, resulting in distortion-free voltage and current in Fig. 6. Therefore, positive-sequence voltage at PCC is used in the following simulation. After further measuring the values of positivesequence reactive current and PCC voltage, only the case using positive-sequence voltage fulfills requirement in Fig. 3. Nevertheless, fault current in both cases is above $1.2 \mathrm{pu}$. This is because the uncontrolled negative-sequence current transformed into positive-sequence SRF introduces oscillating steady-state error. Even though the overcurrent can be mitigated by increasing the bandwidth of PI controller, it cannot be nullified completely as a high gain might lead to instability. Therefore, it is necessary to include controller that regulates negative-sequence current.

\section{B. Balanced Current Control}

As illustrated in Fig. 7, a set of balanced fault current within limit is obtained after initial transient under unbalanced faults. The output active power and reactive power are oscillating at twice fundamental frequency with the same amplitude. With the current being controlled in positive- and negative-sequence separately, the current controller doesn't have steady-state error and the reactive current requirement specified in Fig. 3 can be satisfied.
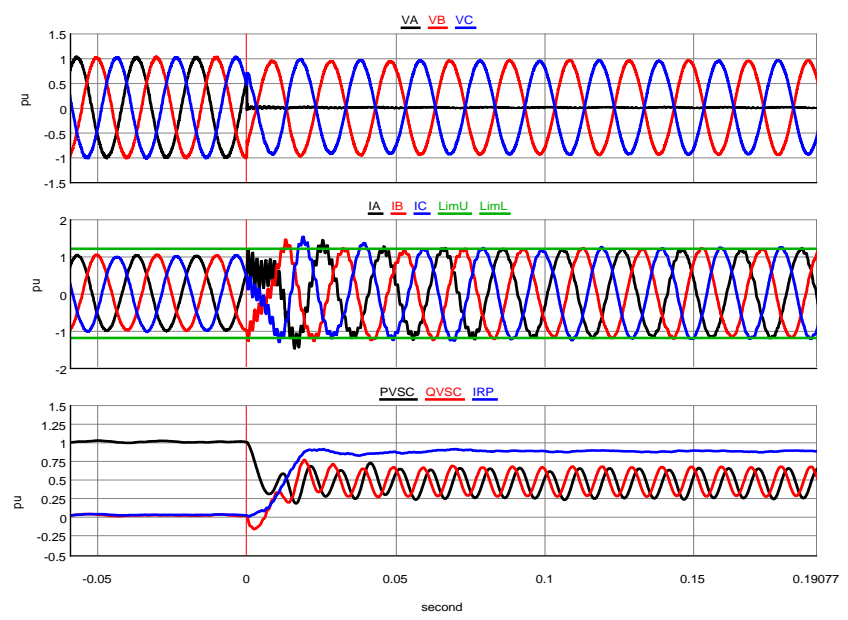

Figure 7. Simulation Results with Balanced Current Control

\section{Constant Active Power Control}

Constant active power control gives an oscillation-free active power during unbalanced faults as shown in Fig. 8. However, a set of unbalanced fault current is injected to the grid. Due to the concern of 1.2 pu current limit and priority of reactive current injection, the requirement in Fig.3 is not fulfilled and the available active power is reduced to almost zero. It is worth mentioning that if the converter current limit is large enough, reactive current requirement can still be satisfied. On the other hand, as indicated in (11), both positive-sequence reactive current and negative-sequence reactive current (IRN) contribute to the instantaneous reactive power. In this simulation, positive- and negative-sequence reactive power are injected to the grid at the same time, giving a higher amount of total reactive power compared to balanced current control.

\section{Constant Reactive Power Control}

This control strategy also exhibits unbalanced fault current. Both of the total reactive power and the average value of active power is zero as the converter current limit enforces a reduction in the output power. However, the positivesequence reactive current still maintains at a certain value. In this simulation, even though the converter injects positive- 
sequence reactive power, it also absorbs negative-sequence reactive power, which cancels the positive-sequence one.
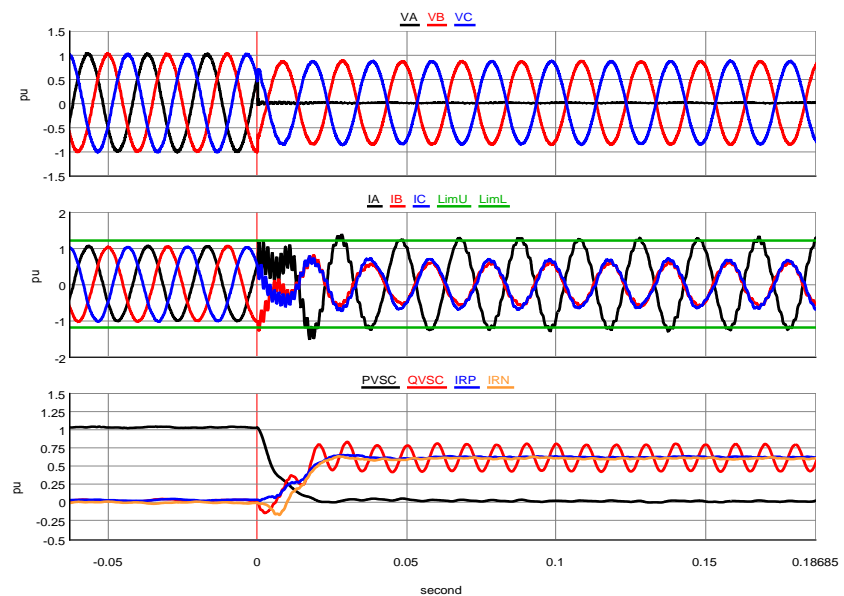

Figure 8. Simulation Results with Constant Acitive Power Control
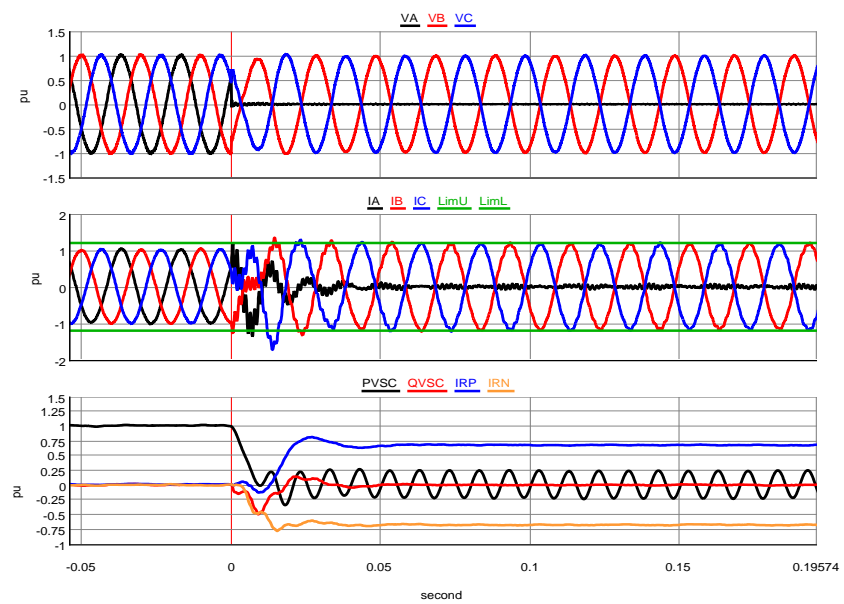

Figure 9. Simulation Results with Constant Reavtive Power Control

\section{CONCLUSION}

To investigate the performance of grid-connected VSCs under unbalanced faults, conventional positive-sequence SRF control and three different control strategies over negativesequence current is described and simulated in this paper. Reactive power injection and converter current limit are both considered. The result shows that VSCs perform differently under unbalanced faults depending on how their control system is designed. In order to limit converter fault current in each phase, it is essential to control negative-sequence current. According to the simulation results, balanced current control complies with the present voltage support requirement best. However, if unbalanced fault current is required, grid codes should be more specific taking negative-sequence reactive power into account, which can either boost or lower the total reactive power. As an infinite combination of coefficients exists for flexible control method, current limit issue and reactive power injection should be studied exclusively to determine to what extends it can benefit power system operation. Furthermore, as the characteristics of voltage and current at PCC change with different control strategies, studies on the potential impact of converters on protection system should consider unbalanced faults and a variety of control strategies, which are to be performed in future works.

\section{REFERENCES}

[1] "Energy Strategy 2050 - from coal, oil and gas to green energy," Danish Energy Agency, Feb, 2011. [Online]. Available: http://www.efkm.dk/sites/kebmin.dk/files/news/from-coal-oil-and-gasto-green-energy/Energy\%20Strategy\%202050\%20web.pdf

[2] "Network code in HVDC connections", ENTSO-E, Oct. 2015. [Online]. Available: https://www.entsoe.eu/major-projects/networkcode-development/high-voltage-direct-current/Pages/default.aspx

[3] S. M. Holder, L. Hang, and B. K. Johnson, "Investigation of transmission line protection performance in an electric grid with electronically coupled generation," in Proc. North American Power Symposium (NAPS) Conf., Manhattan, Sep. 22-24, 2013.

[4] L. He, L. Chen-Ching, A. Pitto, and D. Cirio, "Distance protection of AC grid with HVDC-connected offshore wind generators," IEEE Transactions on Power Delivery, vol. 29, no. 2, pp. 493-501, Apr. 2014.

[5] A. Roy, B. K. Johnson, "Transmission side protection performance with Type-IV wind turbine system," in Proc. North American Power Symposium (NAPS) Conf., Pullman, Sep. 7-9, 2014.

[6] R. Li, C. Booth, A. Dysko, A. Roscoe, H. Urdal and J. Zhu, "Protection challenges in future converter dominated power systems: demonstration through simulation and hardware tests," in Proc. International Conference on Renewable Power Generation, Beijing, Oct. 17-18, 2015.

[7] G. Saccomando, J. Svensson, and A. Sannino, "Improving voltage disturbance rejection for variable-speed wind turbines," IEEE Transactions on Energy Conversion, vol. 17, no. 3, pp. 422-428, Sep. 2002.

[8] C. Du, A. Sannino and M. H. J. Bollen, "Analysis of response of VSCbased HVDC to unbalanced faults with different control systems," in Proc. IEEE/PES Transmission Distribution Conf. and Exhib.: Asia Pacific, Dalian, Aug, 2005.

[9] C. H. Ng, L. Ran, and J. Bumby, "Unbalanced-grid-fault ride-through control for a wind turbine inverter," IEEE Transactions on Industry Applications, vol. 44, no. 3, pp. 845-856, May/Jun. 2008.

[10] F. Wang, J. L. Duarte, and M. A. M. Hendrix, "Pliant active and reactive power control for grid-interactive converters under unbalanced voltage dips," IEEE Transactions on Power Electronics, vol. 26, no. 5, pp. 1511-1521, May. 2011.

[11] X. Guo, W. Liu, X. Zhang, X. Sun, Z. Lu, and J. M. Guerrero, "Flexible control strategy for grid-connected inverter under unbalanced grid faults without PLL," IEEE Transactions on Power Electronics, vol. 30, no. 4, pp. 1773-1778, Apr. 2015.

[12] "Technical regulation 3.2.5 for wind power plants with a power output above $11 \mathrm{~kW}$, " Energinet.dk, Denmark, Jul. 24 2015. [Online].

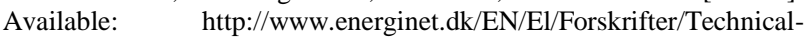
regulations/Sider/Forskrifter-for-nettilslutning.aspx\#3.2.5

[13] M. Curzi, R. Sharma and F. Martin, "In fault ride through reactive current rise time requirements of various European grid codes - analysis based on a full-converter wind turbine," Wind Energy, vol. 19, no. 6, pp. 1121-1133, Jun. 2016.

[14] H. Song and K. Nam, "Dual current control scheme for PWM converter under unbalanced input voltage conditions," IEEE Transactions on Industrial Electronics, vol. 46, no. 5, pp. 953-959, Oct. 1999.

[15] R. Teodorescu, M. Liserre and P. Rodriguez, "Grid converters for photovoltaic and wind power systems", New York: Wiley, Jan. 2011, pp. 237-287.

[16] M. A. Fotouhi, Z. Vale, R. Castro, S. F. Pinto and F. A. Silva, "Flexible operation of grid-interactive converters under unbalanced grid conditions," in Proc. SERSC Advanced Science and Technology Letters, vol. 97 (SUComS 2015), pp. 1-9, 2015. [Online]. Available: http://onlinepresent.org/proceedings/vol97_2015/1.pdf 